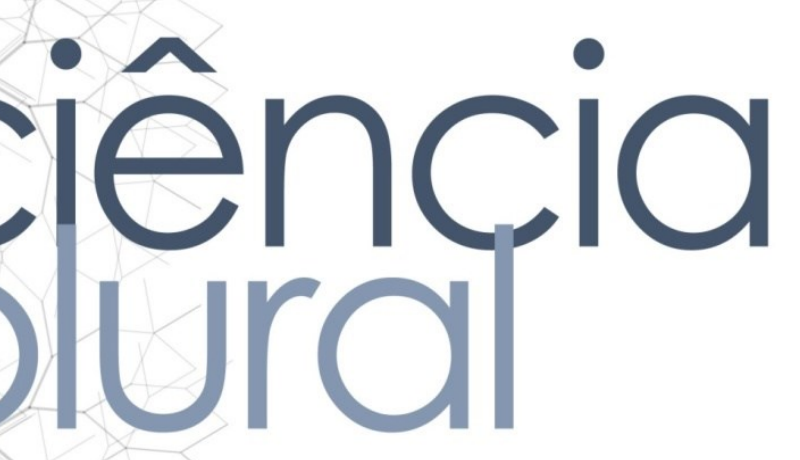

\title{
CONHECIMENTO DE TRABALHADORES RURAIS DE UM MUNICÍPIO DO NORDESTE BRASILEIRO ACERCA DA PREVENÇÃO E DIAGNÓSTICO PRECOCE DO CÂNCER DE BOCA
}

\section{Rural workers's knowledge about early diagnosis and oral cancer prevention in a brazilian northeast municipality}

André Costa Cartaxo - Cirurgião-Dentista; Especialista em Periodontia; Mestre em Saúde Coletiva. E-mail: decocartaxo@yahoo.com.br

Davi Neto de Araújo Silva • Cirurgião-Dentista graduado pela UFRN e Mestrando do PPGSCol - UFRN com área de concentração em Odontologia. E-mail: davinetoaraujo@yahoo.com.br

Kátia Cibele Alves Dantas Costa • Cirurgiã-Dentista. E-mail: katcibel@hotmail.com

Georgia Costa de Araújo Souza • Cirurgiã-Dentista; Mestre em Odontologia; Doutora em Saúde Coletiva; Professora Adjunta do Departamento de Odontologia da UERN. E-mail: georgia_odonto@yahoo.com.br

Ana Rafaela Luz de Aquino Martins - Cirurgiã-Dentista; Especialista em Periodontia; Mestre em Odontologia; Doutora em Patologia Oral; Professora Adjunta do Departamento de Odontologia da UFRN.

E-mail: anarafaela.luz@terra.com.br

Autor responsável pela correspondência:

André Costa Cartaxo. E-mail: decocartaxo@yahoo.com.br 


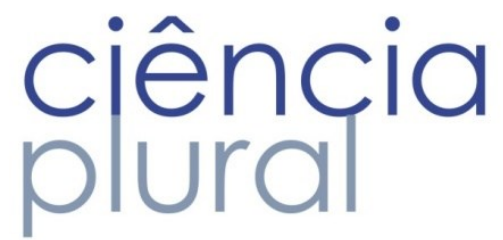

RESUMO

Introdução: $O$ câncer de boca está entre o sexto e o oitavo tipo de câncer mais comum em todo 0 mundo. Dentre os principais fatores de risco relacionados aos tumores malignos orais encontram-se o tabaco, álcool e a radiação solar ultravioleta. A prevenção destes fatores de risco está entre os mais importantes desafios de saúde pública da atualidade. Objetivo: Analisar o conhecimento dos trabalhadores rurais, grupo de risco para câncer de boca, acerca da prevenção e diagnóstico precoce da neoplasia. Métodos: A amostra contou com 100 participantes, sendo os dados coletados através de questionário estruturado com perguntas relativas ao conhecimento sobre o câncer de boca, fatores de risco, diagnóstico precoce e prevenção. Resultados: Os resultados evidenciaram prevalência de indivíduos do sexo feminino, residentes na zona rural, expostos ao sol de 5 a 8 horas por dia. Sobre o conhecimento de câncer de boca, $40 \%$ relacionou-o com algum tipo de doença, $54 \%$ que o principal fator de risco seria a falta de higiene, e $44 \%$ respondeu que a forma de prevenir seria com cuidados de higiene. $29 \%$ dos participantes fazem uso de bebida alcoólica e $14 \%$ de cigarro. Dos entrevistados que utilizam formas de proteção, $71,27 \%$ utilizam apenas chapéu ou boné. Entre os participantes da pesquisa, 91\% nunca realizou o autoexame. Conclusão: Os trabalhadores apresentam desconhecimento a respeito do câncer de boca e fatores de risco associados ao desenvolvimento desta neoplasia. Torna-se indispensável instituir um programa de prevenção e diagnóstico precoce desta doença em populações de risco.

Palavras-Chave: Câncer bucal; Diagnóstico precoce; Prevenção de Doenças; Fatores de risco.

\section{ABSTRACT}

Introduction: Mouth cancer is between the sixth and the eighth most common type of cancer worldwide. Among the main risk factors related to oral malignant tumors are tobacco, alcohol and ultraviolet solar radiation. Prevention of these risk factors is among the most important public health challenges nowadays. Objectives: Analyze the level of knowledge of rural workers, risk group for oral cancer, about prevention and early diagnosis of this neoplasm. Material and Methods: The sample consisted of 100 rural workers, and the data were collected through structured questionnaire with questions regarding knowledge about oral cancer, its risk factors, early diagnosis and prevention of malignancy. Results: The results showed prevalence of females (52\%), living in rural areas (86\%), $44 \%$ exposed to the sun 5-8 hours daily. With respect to knowledge to oral cancer, $40 \%$ associated with some kind of disease, $54 \%$ answered that the main risk factor was the lack of hygiene, and $44 \%$ responded that the way to prevent it would be with hygiene care. It was detected that $29 \%$ of participants consume alcohol and $14 \%$ tobacco. Of the $94 \%$ of participants who use some form of protection, $71.27 \%$ only use hat or cap to protect from the sun. $91 \%$ had never conducted selfexamination. Conclusion: The results showed that rural workers present no knowledge about oral cancer and the risk factors associated with the development of this malignancy. Thus, it becomes essential to establish a program of prevention and early diagnosis of this disease in the risk population.

Key words: Oral cancer, early diagnosis, Disease Prevention, risk factors. 


\section{ciência plural}

\section{Introdução}

O câncer de boca, também intitulado câncer oral, é o oitavo tipo de câncer mais comum em todo 0 mundo, com incidência de mais de 300.000 novos casos anuais ao redor do globo ${ }^{1}$. No Brasil, estima-se o surgimento de 11.140 novos casos de câncer da cavidade oral em homens e 4.350 em mulheres, no ano de 2016, tornando-o um dos tipos de tumores malignos mais comuns na população brasileira ${ }^{*}$. Na região Nordeste, o câncer oral é o quarto mais frequente em homens e o oitavo em mulheres, sendo que para 0 estado do Rio Grande do Norte, a incidência prevista é de 5 a $7 \%$ de todas as neoplasias malignas ${ }^{3}$.

Dentre os principais fatores de risco relacionados aos tumores malignos orais encontram-se 0 tabaco, álcool e a radiação solar ultravioleta (UV) ${ }^{1,3}$, dos quais, este último é o principal fator de risco para o desenvolvimento do câncer de lábio4. Assim como também, pessoas com baixo nível socioeconômico e nível de escolaridade mais baixa apresentam maior incidência de câncer de boca e maior mortalidade, assim como também baixa qualidade de vida e sobrevida ${ }^{1,5}$. Portanto, na Região Nordeste do Brasil, particularmente no estado do Rio Grande do Norte, com grande exposição solar durante a maioria dos dias do ano, os trabalhadores cujo trabalho é a céu aberto como os agricultores, pecuaristas, pescadores e trabalhadores da construção civil merecem uma atenção especial para a atuação das equipes de saúde na prevenção do câncer de boca, em especial o câncer de lábio inferior.

A prevenção e o controle de câncer estão entre os mais importantes desafios científicos e de saúde pública da atualidade ${ }^{3}$. De acordo com Registros Hospitalares de Câncer, a maioria dos pacientes brasileiros chega aos hospitais com a doença em fase avançada. Isso faz com que o tratamento desses casos deixe de ser curativo para, na maioria das vezes, ser mutilante, o que influencia sobremaneira a sobrevida desses pacientes ${ }^{6}$. As causas mais importantes no atraso do diagnóstico são a evolução inicial oligossintomática, o reduzido conhecimento sobre a doença entre pacientes e profissionais, o medo do diagnóstico e as dificuldades ao acesso médico.

Em virtude da importância da prevenção, diagnóstico e tratamento precoce do câncer de boca para o prognóstico do carcinoma epidermóide oral, bem como do planejamento de ações preventivas direcionadas às necessidades da população-alvo, este estudo se propôs a avaliar o nível de conhecimento dos trabalhadores rurais do município de Caicó acerca da prevenção e diagnóstico precoce do câncer de boca. 


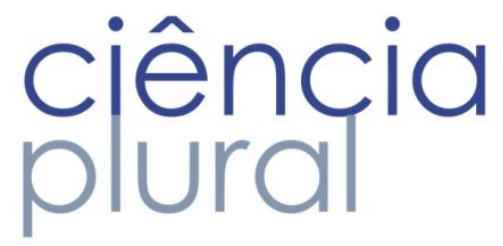

\section{Métodos}

Esta pesquisa, aprovada pelo Comitê de ética em Pesquisa da Universidade do Estado do Rio Grande do Norte, sob número 069/2011, consistiu em um estudo exploratório, de diagnóstico, sobre o nível de conhecimento dos trabalhadores rurais do município de Caicó, sobre o câncer de boca, caracterizandose como um estudo transversal.

A amostra consistiu de 100 trabalhadores rurais cadastrados no Sindicato dos Trabalhadores Rurais do Município de Caicó. 0 cálculo da amostra foi realizado após estudo piloto inicial com 40 indivíduos. Para uma prevalência de 50\%, e margem de erro de $20 \%$, o número calculado foi de 96 indivíduos, sendo então totalizado uma amostra de 100 participantes. 0 instrumento utilizado para a coleta de dados foi a entrevista estruturada, aplicada entre fevereiro de 2012 e junho de 2013, sendo os participantes voluntários abordados no Sindicato em momentos prévios às reuniões realizadas no sindicato e/ou ao atendimento odontológico que acontece no mesmo local e que é exclusivo para o grupo em questão.

O critério de inclusão consistiu em trabalhadores rurais cadastrados no Sindicato citado, sendo excluídos da amostra trabalhadores não cadastrados ou os que se recusaram a participar da pesquisa. Os trabalhadores foram convidados a responder, mediante entrevista, um questionário aplicado pelos pesquisadores, contendo dados de identificação social do entrevistado, e perguntas específicas sobre 0 câncer de boca, com o intuito de identificar o nível de conhecimento dos participantes acerca da prevenção e diagnóstico precoce desta patologia (anexo I). As perguntas foram explicadas em linguagem popular, para melhor compreensão pelo entrevistado.

Os resultados obtidos foram digitados em planilha eletrônica Excel (Microsoft Office 2010) e submetidos à estatística descritiva. Para a análise descritiva, os parâmetros avaliados foram separados em grupos que congregassem respostas semelhantes, para melhor apreciação dos dados.

\section{Resultados}

\section{Índices sociais}

Com relação ao gênero dos participantes, foi constatada uma relativa equivalência entre o gênero feminino $(n=52 ; 52 \%)$ e masculino $(n=48,48 \%)$. Do total da amostra, houve predomínio entre as faixas etárias de 20 a 59 anos, somando um total de $77 \%(n=77)$, sendo $6 \%$ entre 10 e 19 anos e $17 \%$ ( $n=17)$ 


\section{ciência \\ plural}

com 60 anos ou mais. Os participantes da pesquisa apresentaram em sua maioria um baixo nível de escolaridade, com $75 \%$ dos entrevistados cursando até 7 anos de educação formal (Gráfico 1).

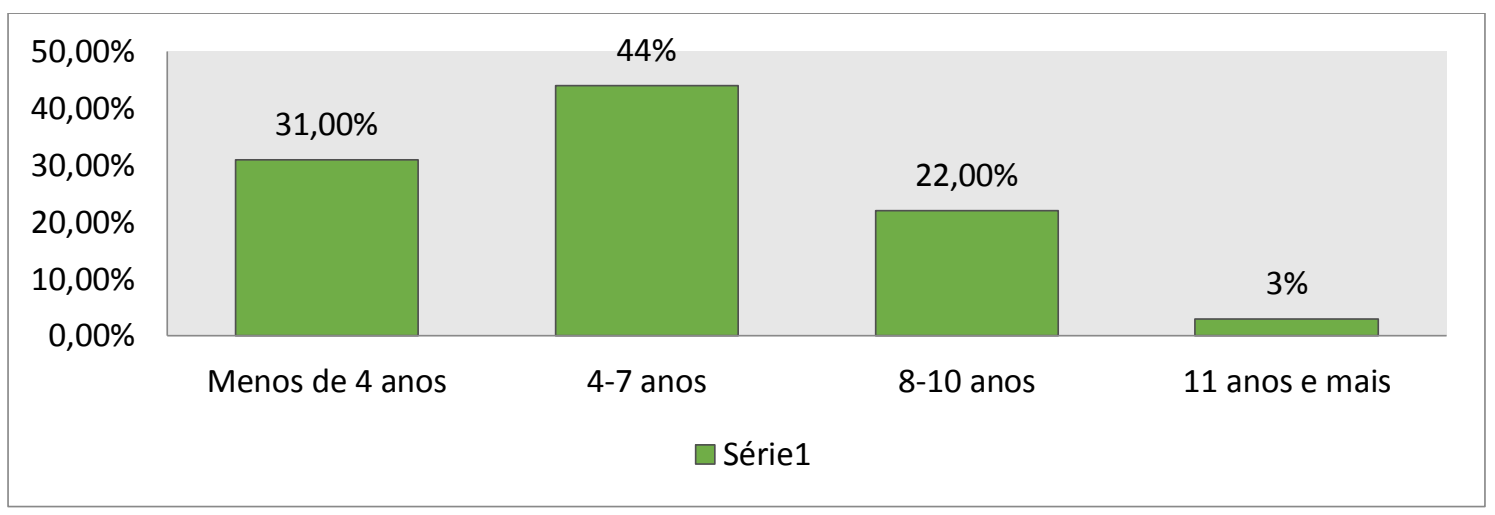

Gráfico 1: Nível de escolaridade (anos de estudo) dos participantes da pesquisa com prevalência da baixa escolaridade. Caicó/RN, 2017.

Quanto ao local de moradia, 86\% $(n=86)$ dos trabalhadores residem na zona rural e 14\% $(n=14)$ na zona urbana, vivendo em sua maioria $(n=68 ; 68 \%)$, com apenas 1 salário mínimo. Em relação ao tempo de trabalho na agricultura foi encontrado que $33 \%(n=33)$ dos participantes possuem entre 6 e 10 anos de trabalho, seguido daqueles com 11 a 25 anos $(n=30 ; 30 \%)$, mais de 25 anos $(n=28 ; 28 \%)$ e 2 a 5 anos $(n=9 ; 9 \%)$. Estes trabalhadores também foram questionados quanto ao tempo de exposição solar diário e $54 \%(n=54)$ relataram ficarem expostos mais de 4 horas por dia, enquanto apenas $46 \%(n=46)$ expõem-se de 1 a 4 horas por dia (Gráfico 2).

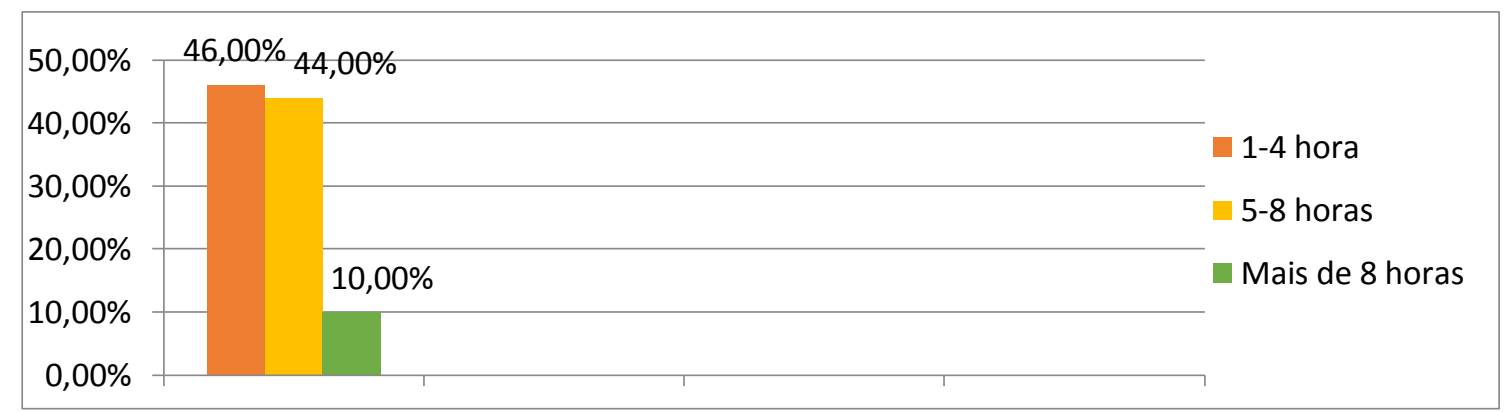

Gráfico 2: Exposição solar diária dos trabalhadores rurais. Caicó/RN, 2017.

\section{Conhecimento sobre câncer}

Em se tratando do conhecimento dos trabalhadores a respeito do câncer de boca, os mesmos apresentaram variadas respostas sobre o que é o câncer de boca. As respostas semelhantes foram separadas em diferentes grupos. Do total da amostra, $40 \%(n=40)$ responderam que o câncer de boca 


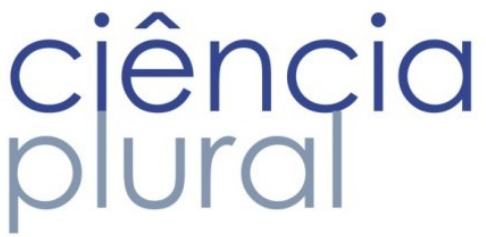

era ou estava relacionado a uma doença. $33 \%(n=33)$ relacionaram o câncer de boca a nódulos e feridas, $6 \%,(n=6)$ relacionaram a fumar e/ou beber, $1 \%,(n=1)$ a fatores genéticos e $4 \%(n=4)$ não souberam responder (Gráfico 3).

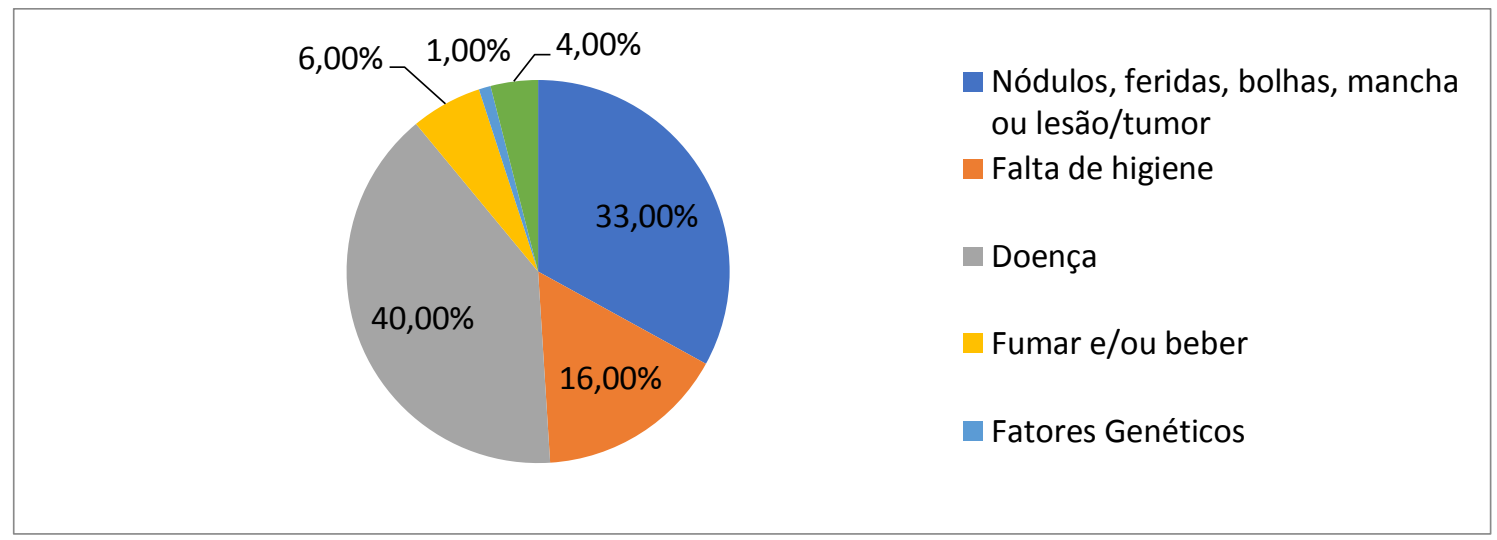

Gráfico 3: Conhecimento dos trabalhadores rurais sobre o que é o câncer de boca. Caicó/RN, 2017.

Os participantes também foram questionados acerca do conhecimento sobre os fatores de risco associados ao desenvolvimento do carcinoma epidermóide oral, sendo observado que $54 \%$ ( $n=54$ ) responderam que os fatores de risco para o câncer de boca estão associados à falta de higiene e cuidados bucais, 16\% ( $n=16)$ não souberam responder, 18\% $(n=18)$ relacionaram aos hábitos de fumar e beber, $5 \%(n=5)$ relacionaram a exposição solar, $2 \%(n=2)$ relacionaram à alimentação, além de outros como uso de próteses $(n=2 ; 2 \%)$, uso de remédios $(n=1 ; 1 \%)$, predisposição genética $(n=1 ; 1 \%)$ e traumas $(n=1 ; 1 \%)$.

\section{Prevenção}

Outro questionamento aos participantes foi o conhecimento deles sobre como prevenir o câncer de boca. Quarenta e quatro por cento $(n=44)$ relacionou a prevenção aos cuidados de higiene bucal, $27 \%$ $(n=27)$ relacionou a visitas periódicas a um profissional de saúde, $13 \%(n=13)$ relacionou a não fumar ou beber; $4 \%(n=4)$ relacionou a proteção solar, $1 \%(n=1)$ relacionou ao uso de remédios, $1 \%(n=1)$ relacionou a não ter muitos relacionamentos e 1\% $(n=1)$ relatou que uma forma de prevenir é evitando traumas, $1 \%(n=1)$ descreveu que preveniria repousando e ainda $4 \%(n=4)$ não soube responder. Os trabalhadores rurais também foram questionados quanto à realização do autoexame do câncer de boca. $91 \%(n=91)$ de todos os participantes da pesquisa relatou nunca ter realizado o autoexame para detecção de câncer oral e apenas 9 (9\%) já havia realizado pelo menos uma vez. Foi observado ainda que $97 \%$ dos participantes, ao ser questionado quanto à conduta que teria diante do aparecimento de lesão suspeita de 


\section{ciência \\ plural}

carcinoma epidermóide oral, respondeu que procuraria um profissional de saúde para realização do tratamento e $3 \%(n=3)$ não soube responder. Outro fato importante encontrado na pesquisa foi que $97 \%$ ( $n=97)$ dos entrevistados relatou nunca ter ouvido explicação sobre câncer de boca. Apenas 3\% $(n=3)$ já tinham ouvido explicações sobre o câncer de boca, sendo que $66,6 \%(n=2)$ ouviu através da televisão e $33,3 \%(n=1)$ ouviu na escola.

\section{Hábitos}

Em relação aos hábitos, quatorze entrevistados (14\%) faziam uso de tabaco. Dentre estes $57,1 \%$ $(n=8)$ faziam uso do tabaco entre $5-15$ anos, $42,8 \%(n=6)$ há 16 ou mais anos. 0 uso de bebida alcoólica foi relatado em 29\% ( $n=29)$ da amostra. Quanto ao uso de utensílios para a proteção solar, $6 \%(n=6)$ dos trabalhadores rurais não usam nenhum tipo de proteção ao trabalhar exposto ao sol. Dentre as formas de proteção mais utilizadas se destacou o uso de boné ou chapéu $(n=67 ; 71,27 \%)$, seguido pelo protetor solar ( $n=25 ; 26,59 \%$ ) e outras forma de proteção (pano na cabeça, óculos e guarda sol) ( $n=2 ; 2,12 \%$ ) (Gráfico 4).

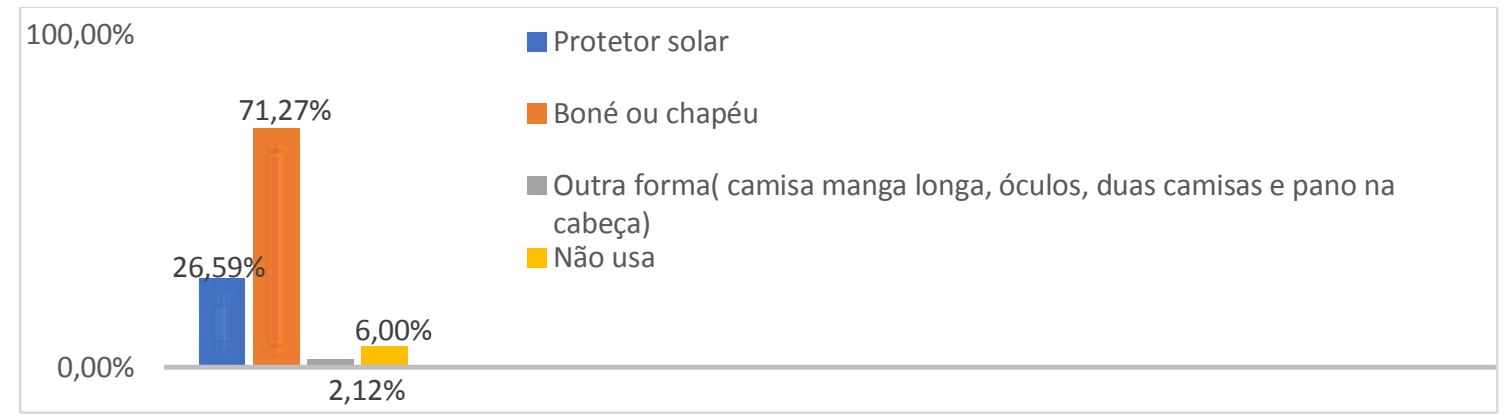

Gráfico 4: Formas de proteção solar utilizadas pelos participantes. Caicó/RN, 2017.

Por fim, 43\% $(n=43)$ destes trabalhadores rurais estavam realizando tratamento odontológico, estando a apenas 1 mês ou menos da última visita, sendo que 21\% ( $n=21)$ estava entre 2 e 6 meses, $16 \%(n=16)$ entre 7 e 12 meses, $12 \%(n=12)$ entre 13 e 48 meses e $8 \%(n=8)$ a mais de 100 meses.

\section{Discussão}

O carcinoma epidermóide oral é a neoplasia maligna oral mais comum, associado a uma alta morbidade e mortalidade ${ }^{7,8,10}$, correspondendo por 25 a 30\% de todos os carcinomas orais 7,9 . Devido à sua alta prevalência em trabalhadores rurais, é necessário que esta população conheça a patologia e a 
importância do seu diagnóstico e prevenção, em especial o câncer de lábio para melhor controle dessa doença.

No presente estudo foi observada uma relativa equivalência entre os gêneros dos participantes, com maioria do gênero feminino 52\%. A maior prevalência do gênero feminino tem sido associada ao papel da mulher na sociedade atual ${ }^{11}$. De fato, estudos recentes têm apresentado alterações nos resultados em relação à frequência de câncer oral. Uma diminuição na incidência de carcinoma epidermóide oral em homens e um aumento entre as mulheres e grupos jovens têm sido observados ${ }^{10,12}$. Este fato tem sido atribuído, às mudanças nos hábitos das mulheres como o trabalho externo e consumo de álcool e tabaco e o aumento de infecção pelo HPV 13,14,15,16.

A amostra deste estudo foi constituída primariamente por participantes com poucos anos de estudo (75\% até 7 anos de estudo) e renda de 1 salário mínimo (68\%), consistindo em um baixo perfil socioeconômico dos participantes que possuem conhecimento inadequado sobre câncer em geral, concordando com o estudo de Biasoli et al. $(2016)^{7}$ que afirmam existir uma relação direta entre o perfil socioeconômico, o acesso à informação e serviços básicos de saúde, sendo o conhecimento dos fatores de risco a base para prevenção efetiva do carcinoma epidermóide oral.

Segundo Santos, Batista e Cangussu (2010) ${ }^{18}$ quanto menor o índice de escolaridade, menor o nível de entendimento e informação dos sujeitos, sendo então a escolaridade, fator determinante para 0 entendimento de informações relevantes sobre o câncer de boca. $O$ baixo nível de anos de estudo dificulta o diagnóstico precoce, pelo fato de que as lesões iniciais, geralmente assintomáticas, não são valorizadas pelo próprio indivíduo. De acordo com Patel et al. (2011) ${ }^{19}$, a prevenção primária dessa condição está embasada nos fatores etiológicos e nas alterações de estilo de vida. De fato, os dados referentes ao conhecimento dos trabalhadores rurais a respeito do câncer de boca exibiram variadas respostas, sendo a maior parte vaga, o que demonstrou conhecimento muito limitado acerca do que é o câncer de boca (73\% relacionou a doença, nódulos ou feridas).

Em relação ao conhecimento sobre os fatores de risco associados ao desenvolvimento do carcinoma epidermóide oral, de modo semelhante, houve uma ampla variação de respostas. A maior parte relatou como fator de risco a falta de higiene e cuidados bucais. Houve também associação com hábitos de fumar e beber, uso de próteses, uso de remédios, predisposição genética e traumas. Além disso, 16\% dos participantes não soube responder. Dessa forma, a maioria dos entrevistados não sabia o que eram fatores de risco e pouco relatou os principais fatores de risco associados ao carcinoma epidermóide oral. Na realidade, $97 \%$ dos participantes relataram nunca ter ouvido explicações acerca da patologia.

Para os trabalhadores rurais, a exposição solar crônica é um importante fator de risco. Ela pode levar ao desenvolvimento do câncer de lábio, principalmente o inferior, já que os raios solares incidem 


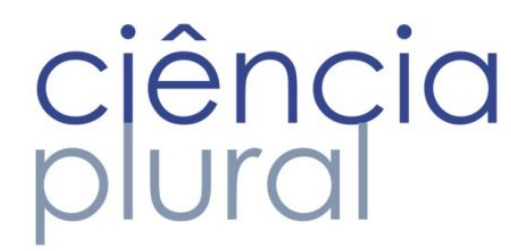

diretamente nesta região que está em sua maioria das vezes desprotegida, levando ao surgimento inicial de uma lesão cancerizável, a queilite actínica, que pode posteriormente progredir para uma lesão maligna20, 21. Importante enfatizar que esta população foi constituída em sua maioria por mulheres que apesar de exercerem suas atividades fora de casa, realizam atividades mais leves ficando menos tempo expostas ao sol, como limpeza da terra, colheita, cuidados dos animais e cultivo de hortas ${ }^{11}$. E ainda, foi observado que a maioria dos participantes não utiliza a forma correta de proteção, uma vez que para que a mesma seja efetiva é necessário o uso do protetor solar e protetor labial. Na presente pesquisa foi encontrado que $29 \%$ dos participantes fazem uso de bebida alcoólica e $14 \%$ usam o tabaco. Destes usuários, quase metade possui o hábito há mais de 16 anos, caracterizando um longo período de exposição 22 .

De fato, o conhecimento limitado sobre o que é o câncer de boca, parece estar associado sobre informações gerais advindas de outros tipos de cânceres ${ }^{20}$. Os principais fatores relacionados à prevenção, que são amplamente importantes para o diagnóstico precoce, tais como o uso do protetor solar e a não utilização de tabaco e álcool, foram pouco relatados na presente pesquisa, com fuga da delimitação do que encontramos na literatura. Lucena, Costa, Silveira e Lima $(2014)^{23}$, ressaltam a importância do uso correto dos fatores de prevenção, como a reaplicação do protetor solar e o recobrimento da pele exp osta ao sol, pois, além da exposição direta, há também a exposição indireta aos raios UV. No mesmo estudo, há uma ligação entre a falta de conhecimentos/baixo nível de escolaridade e o uso correto de métodos de prevenção.

Uma das principais formas de prevenção e diagnóstico precoce do câncer de boca é a realização do autoexame da boca. No estudo foi observado que apenas $9 \%$ já realizou 0 autoexame em algum momento de suas vidas, fato que muitas vezes se relaciona a um diagnóstico tardio do câncer. 0 autoexame é um exame visual e tátil que deve ser realizado pelo próprio paciente, e de extrema importância para o diagnóstico precoce. 0 ideal é realizar o autoexame da boca a cada 3 meses, para que qualquer alteração da normalidade seja prontamente detectada. De acordo com a literatura ${ }^{10}$, a técnica do autoexame é descrita geralmente como um método não-invasivo, de baixo custo, confiável e aplicável em massa para controlar incidência de carcinoma epidermóide oral. Além disso, seus benefícios seriam direcionados para a prevenção secundária. O paciente seria capaz de identificar lesões suspeitas de malignidade e, em seguida, encaminha-se a uma unidade de saúde. A boca é um sítio anatômico de fácil acesso para exame, permitindo que o paciente, através do autoexame, possa visualizar diretamente alterações suspeitas, principalmente nos estágios iniciais, levando ao diagnóstico precoce ${ }^{1,18}$.

Por fim, apenas 3\% dos trabalhadores já ouviram explicações sobre o câncer de boca, apesar de $43 \%$ estarem em tratamento odontológico, estando a 1 mês ou menos da última consulta odontológica. 


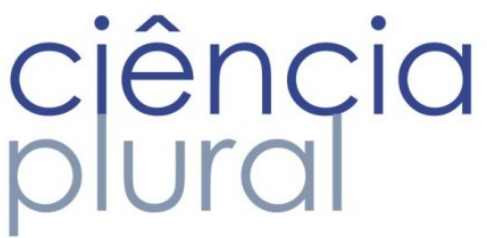

Isto enfatiza a necessidade de maior empenho dos profissionais de saúde, principalmente cirurgiõesdentistas, quanto à orientação sobre prevenção e diagnóstico precoce do câncer de boca, uma lesão de fácil detecção, muitas vezes para o próprio paciente, e que quando diagnosticada em estágios iniciais aumenta significativamente a sobrevida dos mesmos ${ }^{24}$. 0 câncer de boca é uma doença de alta incidência no mundo, considerada problema de saúde pública, sendo a prevenção e o diagnóstico precoce, as melhores formas de combater a doença.

\section{Conclusão}

Foi possível observar que falta informação à população em geral, e principalmente as populações de maior risco, como a população de estudo, acerca do câncer oral, incluindo sobre a prevenção e diagnóstico precoce. Dessa forma, existe a necessidade da inclusão de orientação básica do câncer oral nas consultas e atendimentos de rotina do cirurgião-dentista. A criação de programas que esclareçam a importância da definição, prevenção e diagnóstico precoce do câncer oral, também é uma necessidade vigente no Estado.

\section{Declaração de conflito de interesses}

Os autores declaram não haver conflito de interesses.

\section{Referências}

1. Al-Jaber A, Al-Nasser L, El-Metwally A. Epidemiology of Oral Cancer in Arabic Countries. Saudi Med J. 2016;37(3):249-255.

2. Instituto Nacional de Câncer José Alencar Gomes da Silva. Estimativa 2016: incidência de câncer no Brasil. Rio de Janeiro RJ: INCA, 2016.

3. Amtha R, Zain R, Razak IA, Basuki B, Roeslan BO, Gautama W, et al. Dietary patterns and risk of oral cancer: a factor analysis study of a population in Jakarta, Indonesia. Oral Oncol. 2009 Aug;45(8):e4953.

4. Domínguez-Gordillo $A$ et al. The pattern of lip cancer occurrence over the 1990-2011 period in public hospitals in Madrid, Spain. J Oral Pathol Med 2016;45:202-210.

5. Júnior SAS. Etiopatogenia do câncer bucal: fatores de risco e de proteção. SaBios-Ver. 2010;1(2):48-58.

6. Bhide SA; Nutting CM. Advances in radiotherapy for head and neck cancer. Oral Oncol. 2010;46(6):439-441. 


\section{ciência plural}

7. Biasoli ER et al. Lip cancer: a clinicopathological study and treatment outcomes in a 25-year experience. J Oral Maxillofac Surg 2016;74:1360-1367.

8. Kenborg L, Jørgensen AD, Budtz-Jørgensen E, Knudsen LE, Hansen J. Occupational exposure to the sun and risk of skin and lip cancer among male wage earners in Denmark: a population-based casecontrol study. Cancer Causes Control. 2010 Aug;21(8):1347-55.

9. Dahlstrom KR, Little JA, Zafereo ME, Lung M, Wei Q, Sturgis EM. Squamous cell carcinoma of the head and neck in never smoker-never drinkers: a descriptive epidemiologic study. Head Neck, Malden. 2008 Jan;30(1):75-84.

10. Marocchio LS, Lima J, Sperandio FF. Oral squamous cell carcinoma: an analysis of 1,564 cases showing advances in early detection. J Oral Sci. 2010 Jun;52(2):267-73.

11. López-Jornet $P$, Camacho-Alonso F, molina-Miñano F. Knowledge and attitudes about oral cancer among dentists in Spain. J Eval Clin Pract. 2010 Feb;16(1):129-33.

12. Marques LA, Eluf-Neto J, Figueiredo RAO, Gois-Filho JF, Kowalski LP, Carvalho LB et al. Oral health, hygiene practices and oral câncer. Rev Saude Publica. 2008 Jun;42(3):471-9.

13. Mauricio HA, Matos FCM, Guimarães TMR. Conhecimentos, atitudes e práticas sobre câncer de boca da comunidade atendida pelo PSF de São Sebastião do Umbuzeiro/PB. Rev. Bras. Cir. Cabeça Pescoço. 2009 Jan;38(1):10-14.

14. Mcdowell JD. An overview of epidemiology and common risk factors for oral squamous cell carcinoma. Otolaryngol Clin North Am. 2006 Apr;39(2):277-94.

15. Oliveira LR, Silva AR, Zucalota S. Perfil da incidência e da sobrevida de pacientes com carcinoma epidermóide oral em uma população brasileira. J Bras Patol Med Lab. 2006 Oct;:42(5):385-392.

16. Papageorge MB. Etiology of oral cancer in the young patient: is tongue cancer becoming the other cancer in women? Oral Maxillofac Surg Clin North Am. 2007 May;19(2):163-71.

17. Batista AC. Distinctive clinical and microscopic features of squamous cell carcinoma of oral cavity and lip. Oral Surg Oral Med Oral Pathol Oral Radiol Endod. 2010 Mar;109(3):e74-9.

18. Pontes FS. Squamous cell carcinoma of the tongue and floor of the mouth: analysis of survival rate and independent prognostic factors in the Amazon region. J Craniofac Surg.2011 May;22(3):925-30.

19. Patel SC, carpenter WR, Tyree S, couch ME, weissler M, Hackman T, et al. Increasing incidence of oral Tongue squamous cell carcinoma in young white women, Age 18 to 44 years. J Clin Oncol. 2011 Apr 10;29(11):1488-94.

20. Souza RL. Lip squamous cell carcinoma in a Brazilian population: Epidemiological study and clinicopathological associations. Med Oral Patol Oral Cir Bucal. 2011 Sep 1;16(6):e757-62. 


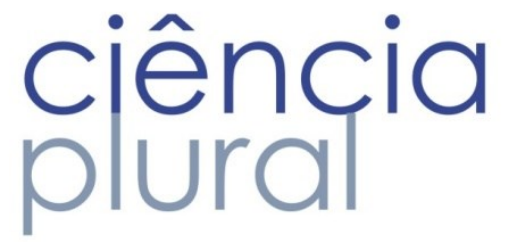

21. Torres-Pereira CC, Angelim-Dias AA, Melo NC, Junior CAL, Oliveira EMF. Abordagem do câncer da boca: uma estratégia para os níveis primário e secundário de atenção em saúde. Cad Saude Publica. 2012;28 Suppl:s30-9.

22. Curado MP, Hashibe M. Recent changes in the epidemiology of head and neck Cancer. Curr Opin Oncol. 2009 May;21(3):194-200.

23. Lucena EES et al. Prevalência de lesões labiais em trabalhadores de praia e fatores de risco. Rev Saúde Pública 2012;46(6):1051-7.

24. Vargas-Ferreira F, Nedel F, Etges A, Gomes APN, Furuse C, Traquinio SBC. Etiologic Factors Associated with Oral Squamous Cell Carcinoma in Non-Smokers and Non-Alcoholic Drinkers: A Brief Approach. Braz Dent J. 2012;23(5):586-90. 